\title{
Significance of Averaging the Lower Link Sensed Forces for Draft Control in Electro-Hydraulic Systems
}

\author{
P.S. Singha*, S. Baishya and R. Sahu \\ Department of Agriculture and Food Engineering, IIT Kharagpur, West Bengal, India \\ *Corresponding author
}

\section{A B S T R A C T}

\begin{tabular}{l}
\hline Ke y w o r d s \\
Draft, EHH, \\
Controller, Three- \\
point linkage, \\
Lower link \\
\hline Article Info \\
\hline $\begin{array}{l}\text { Accepted: } \\
18 \text { May } 2020 \\
\text { Available Online: } \\
\text { 10 June } 2020\end{array}$ \\
\hline
\end{tabular}

With advancement of technology there is now a shift from usage of mechanical hydraulic hitch control systems to electro-hydraulic hitch control systems. For higher horse-power tractors there is a significance of using Lower link sensing for draft control and are mostly used now a days. The dilemma to the tractor manufacturer is which lower link to sense or averaging of the lower link sensed forces is the way out. This paper presents the significance of averaging the lower link forces since it prevents from the ambiguity to the controller. To proof this phenomenon both field test and lab test were conducted through instrumentation. In lab test a weight box testing method was used simulating an implement condition and the results were analysed and presented in this paper. This paper proofs that averaging of lower link forces is necessary for draft sensing in Electrohydraulic hitch system.

\section{Introduction}

With the usage of higher horsepower requirement implements it has become necessary to use lower link draft sensing due to shift of line of pull towards the hitch point causing null sensing forces. The electrohydraulic hitch systems are now been used due to better response time of operation and better quality of field operations. In the subsequent paragraphs this system is explained in detail. Draft control can be done by lower link attaching two load pin sensors on the lower links. But the ambiguity is which one to be used for draft sensing or averaging of the same can be used. The paper presents the study of significance of averaging the lower link draft forces.

\section{System overview}

Fig.1 shows abasic electro-hydraulic hitch system. It is a closed loop system where the draft on the implement, while operation loads the sensor which is sensed by the sensor (in top link and lower link) and taken as a 
feedback signal to the ECU. The operator sets a draft value through operator panel and supplied to ECU. These two values i.e. set draft and sensed draft is subtracted to find the error draft in the controller of the ECU. To minimize the error draft to zero the controller in the ECU supplies flow actuating the control valve opening port area. Flow is supplied to the hydraulic cylinder. Hydraulic cylinder lifts or lowers the implement according to the error draft value. If set draft is more than feedback signal, then lowering of implement takes place otherwise there is lifting of implement.

\section{Characteristic curve of the Sensors used in EHH system}

The characteristic curve is represented as voltage vs Force characteristics of the load pin sensors used in the EHH system. The working principle of these sensors is magneto resistive in nature. This curve was obtained by applying the known load and obtaining the output voltage. The supply voltage was $5 \mathrm{v}$ and in no load the output voltage was $2.5 \mathrm{~V}$.

Similarly, the characteristic curve of the angle sensor which operate on the principle of hall effect was also obtained.

\section{Materials and Methods}

\section{Weight box testing}

Weight box testing was done to study the characteristic behaviour of the lower link sensors, when the loaded lower links were in hanging condition.

\section{No load test}

Initially no load was attached to the lower links. This was done for calibration purpose. The idea being that when no load was attached then the lower links should show 2.5
$\mathrm{V}$ as the output reading which corresponds to zero sensed force, but there may be mounting error, hence it did not show $2.5 \mathrm{~V}$, which was corrected in the software used for analysis.

\section{Load test}

Loads were attached to the lower links after the no load test. The setup is explained below. Weight box was loaded with different loads both even and uneven on the both sides of the weight loader box as shown in Table 4.1. This was done to simulate the uneven loading environment in the field which may be due to unsymmetrical geometry of the implement or uneven draft experienced on the either links.

\section{Results and Discussion}

In Fig 5the results of Time vs. Voltage at no load attached to the three-point hitch have been shown. At no load the voltage reading for top and lower links should be $2.5 \mathrm{~V}$ which corresponds to zero sensed force. But there is sensor offset which is due to mounting of the sensors. Hence voltage correction of the two load pin sensors was done. The result shows an offset correction of $0.037 \mathrm{~V}$ for right lower link and $0.043 \mathrm{~V}$ for left lower link which was fed into controller for correct load calculations.

\section{Load testing}

In load testing both even and uneven loads were attached on the left and right side of the weight box. The weight box weight was 67 $\mathrm{Kg}$. The loading procedure for various test case have been discussed in materials and methods. In Fig 6 shows the result for $80 \mathrm{~kg}$ weight. In Fig 6 (a) $80 \mathrm{~kg}$ weight was applied evenly on the both side of weight box and then the weight box was lifted and lowered. There is $200 \mathrm{~N}$ initial difference in sensed force between the two lower links because the lower links and weight box are not exactly 
symmetric. It is observed in the graph that the lower links experiences compressive force through out the experiment or in the hanging condition the lower links experiences compressive force. In Fig 6 (b) $80 \mathrm{~kg}$ load was applied on the left side hence the difference in the sensed force for both the lower links increased to $660 \mathrm{~N}$. In the left link compressive force decreased or the tension force increased due to application of weight on left side. In both the figures Fig 6 (a) and (b) while raising the weight box the compressive force decreases, because of the changing lower link and lift link angle. If average of both the lower link sensed forces is done for both even and uneven loading case and compared then it can be seen that both follow nearly the same profile with a time lag because duration of experiment is different for both the cases as shown in Fig 6 (c). Similar results were observed for other test cases also.

Table.1 Loading procedure

\begin{tabular}{|c|c|c|}
\hline Test case No. & Left $(\mathbf{K g})$ & Right $(\mathbf{K g})$ \\
\hline $\mathbf{1 .}$ & 0 & 40 \\
\hline $\mathbf{2 .}$ & 0 & 80 \\
\hline $\mathbf{3 .}$ & 0 & 120 \\
\hline $\mathbf{4 .}$ & 40 & 0 \\
\hline $\mathbf{5 .}$ & 80 & 0 \\
\hline $\mathbf{6 .}$ & 120 & 0 \\
\hline $\mathbf{7 .}$ & 40 & 40 \\
\hline $\mathbf{8 .}$ & 80 & 80 \\
\hline $\mathbf{9 .}$ & 120 & 40 \\
\hline $\mathbf{1 0 .}$ & 40 & 120 \\
\hline
\end{tabular}

Figure.1 Basic electro-hydraulic hitch system

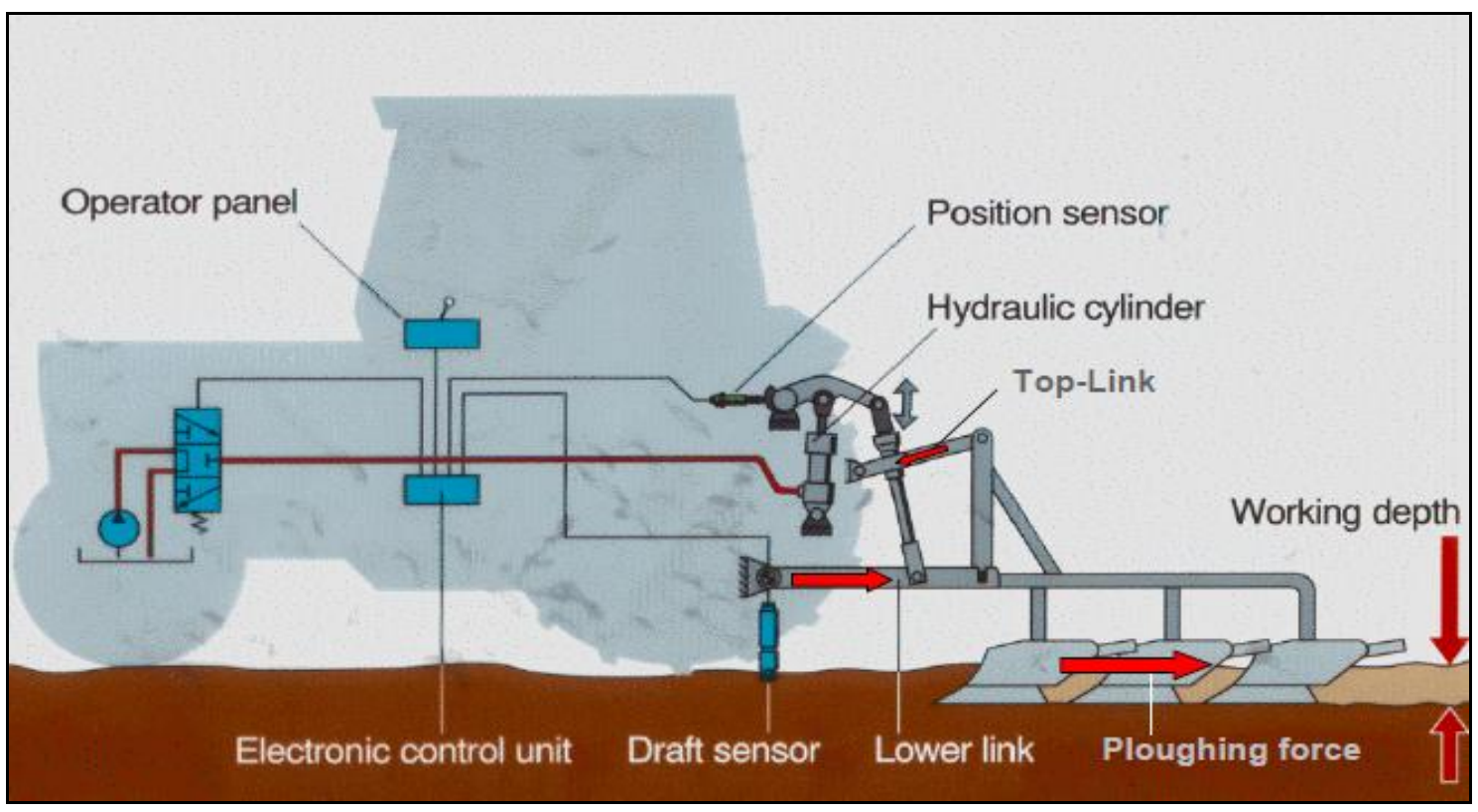


Figure.2 Voltage vs input force of lower link sensor

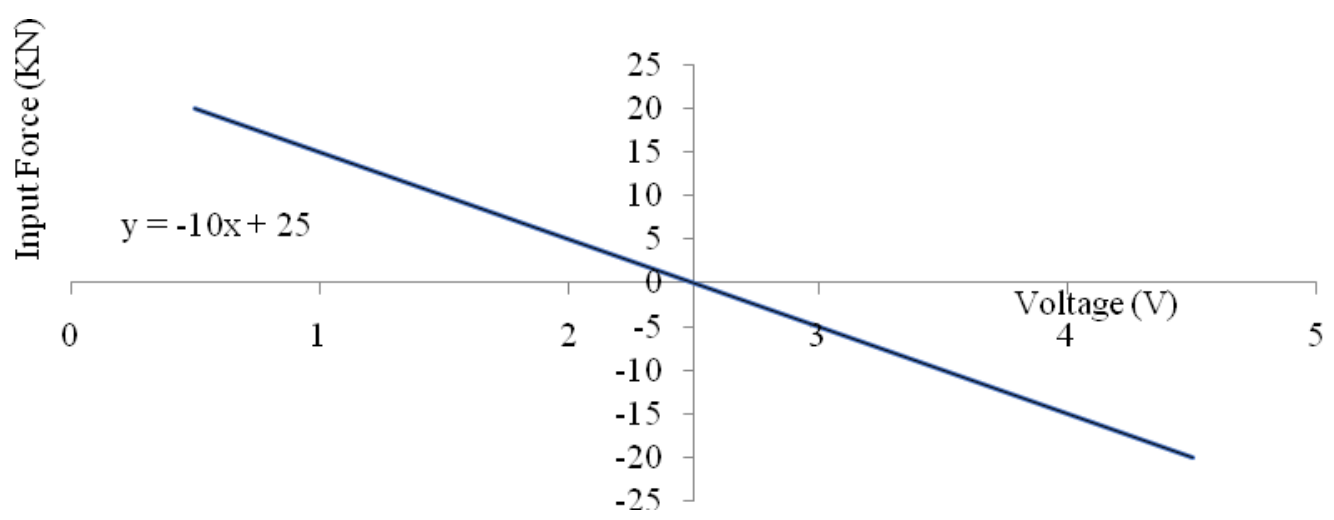

Figure.3 Angle sensor characteristic curve

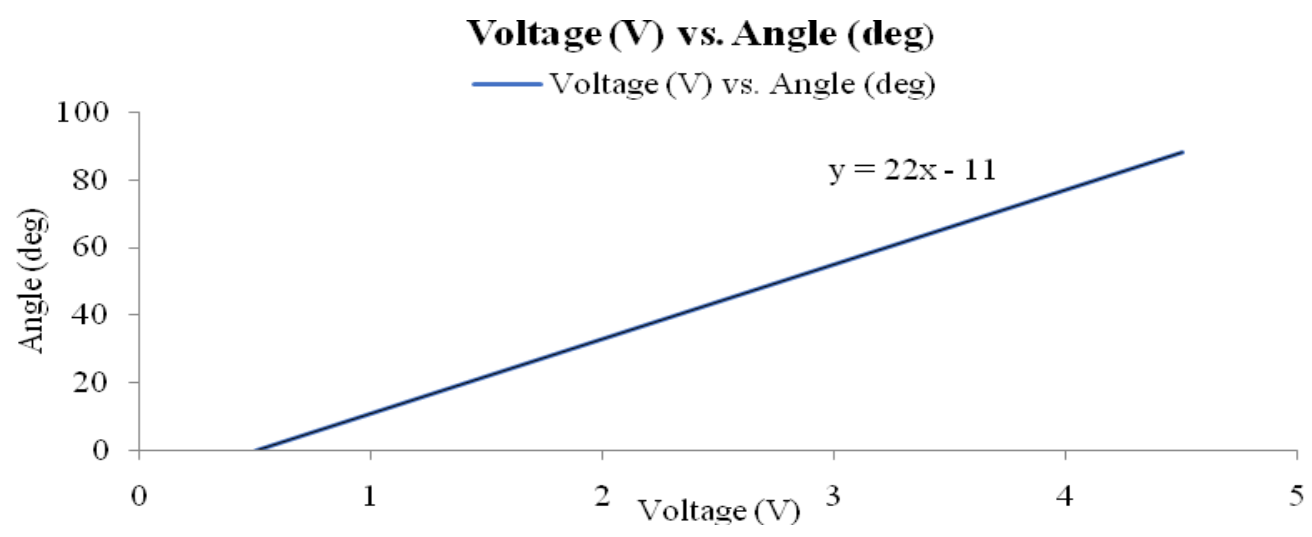

Figure.4 Set up for weight box testing

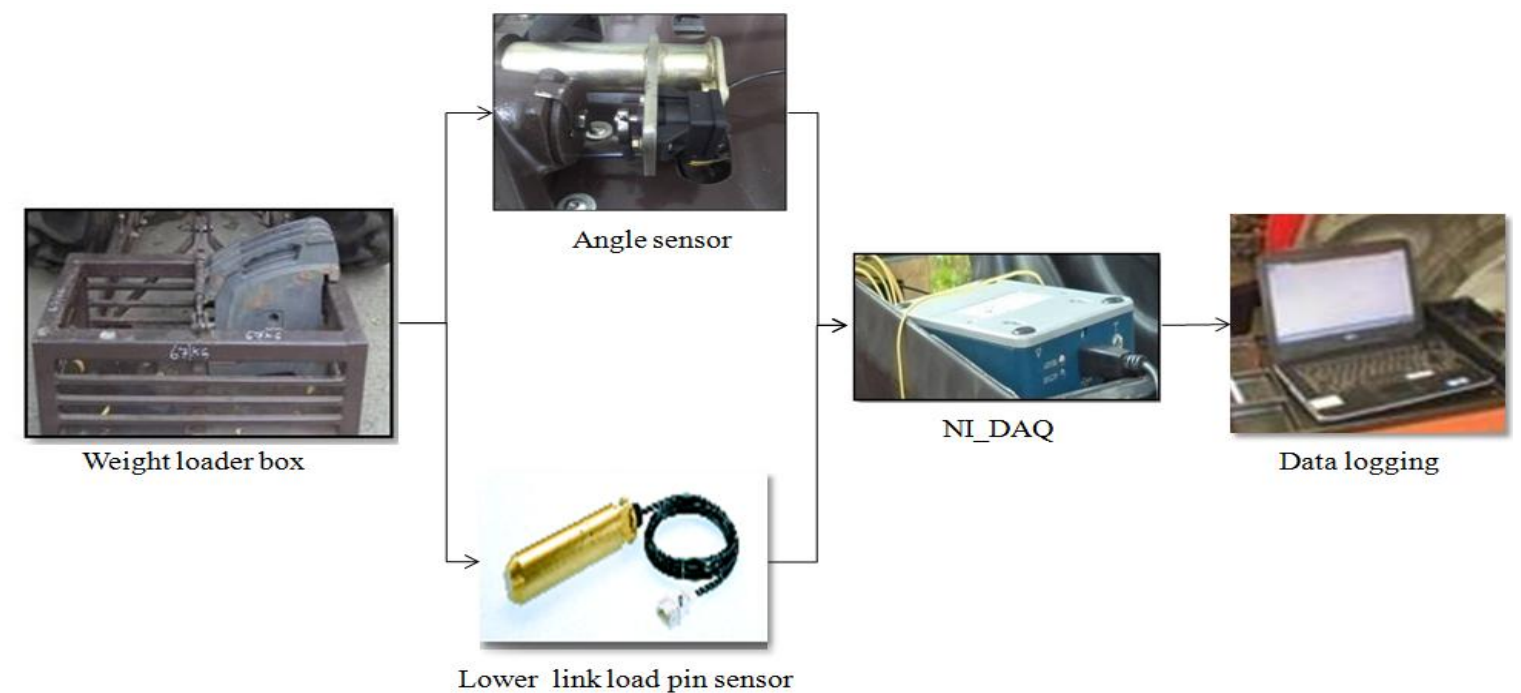


Fig.5 Draft sensor offset correction

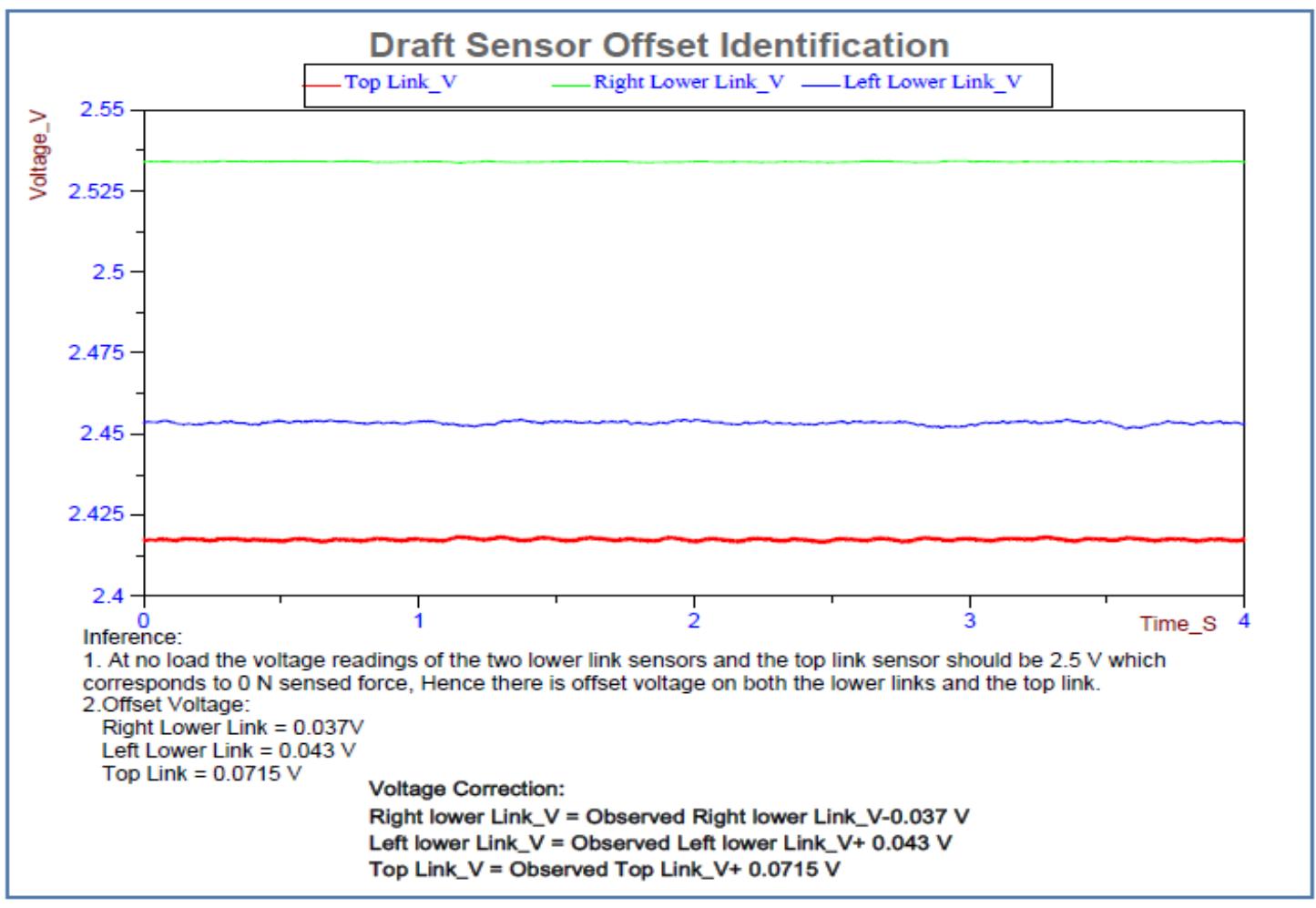

Figure.6(a) Load test - Even loading

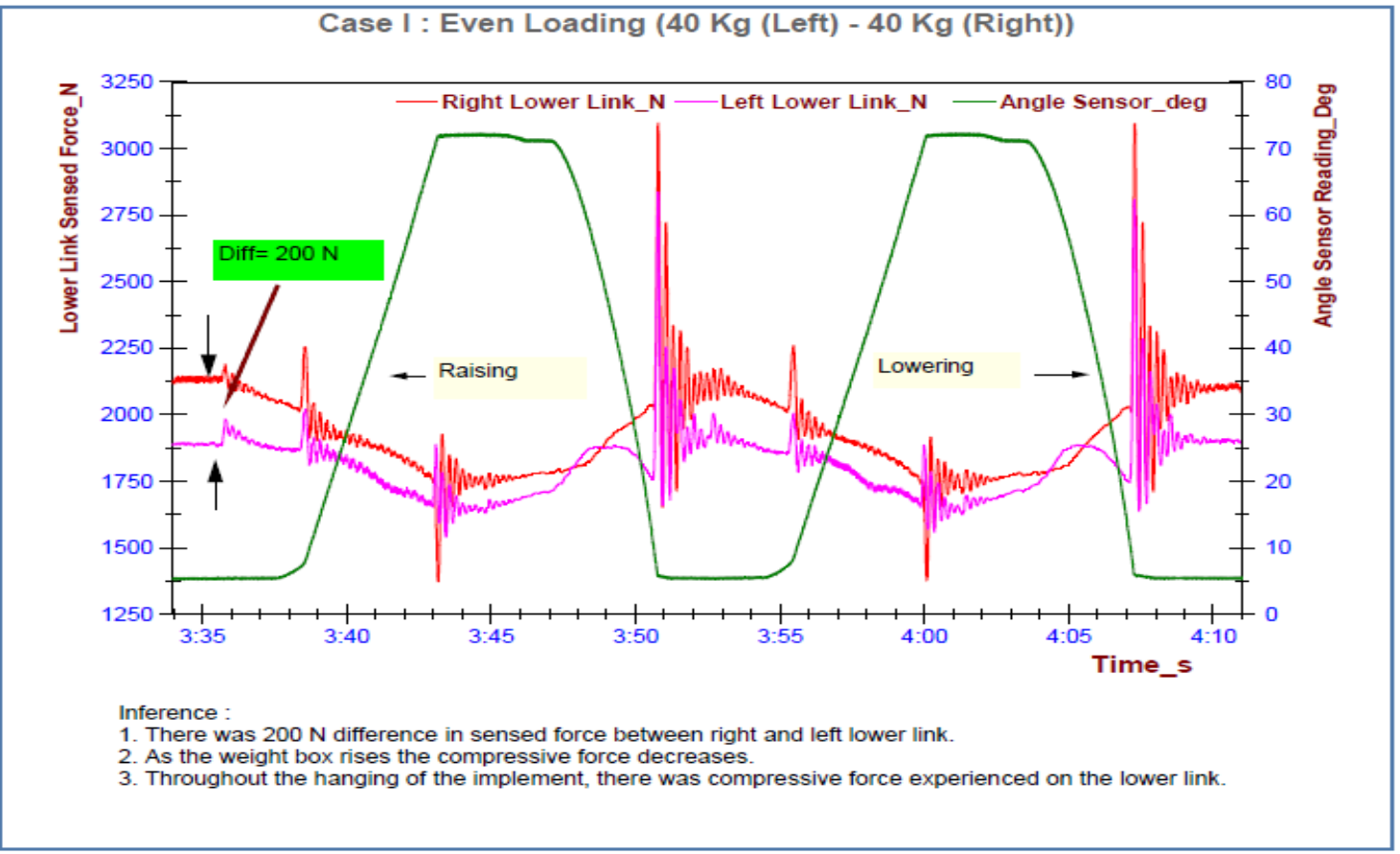


Figure.6(b) Load test - Uneven loading

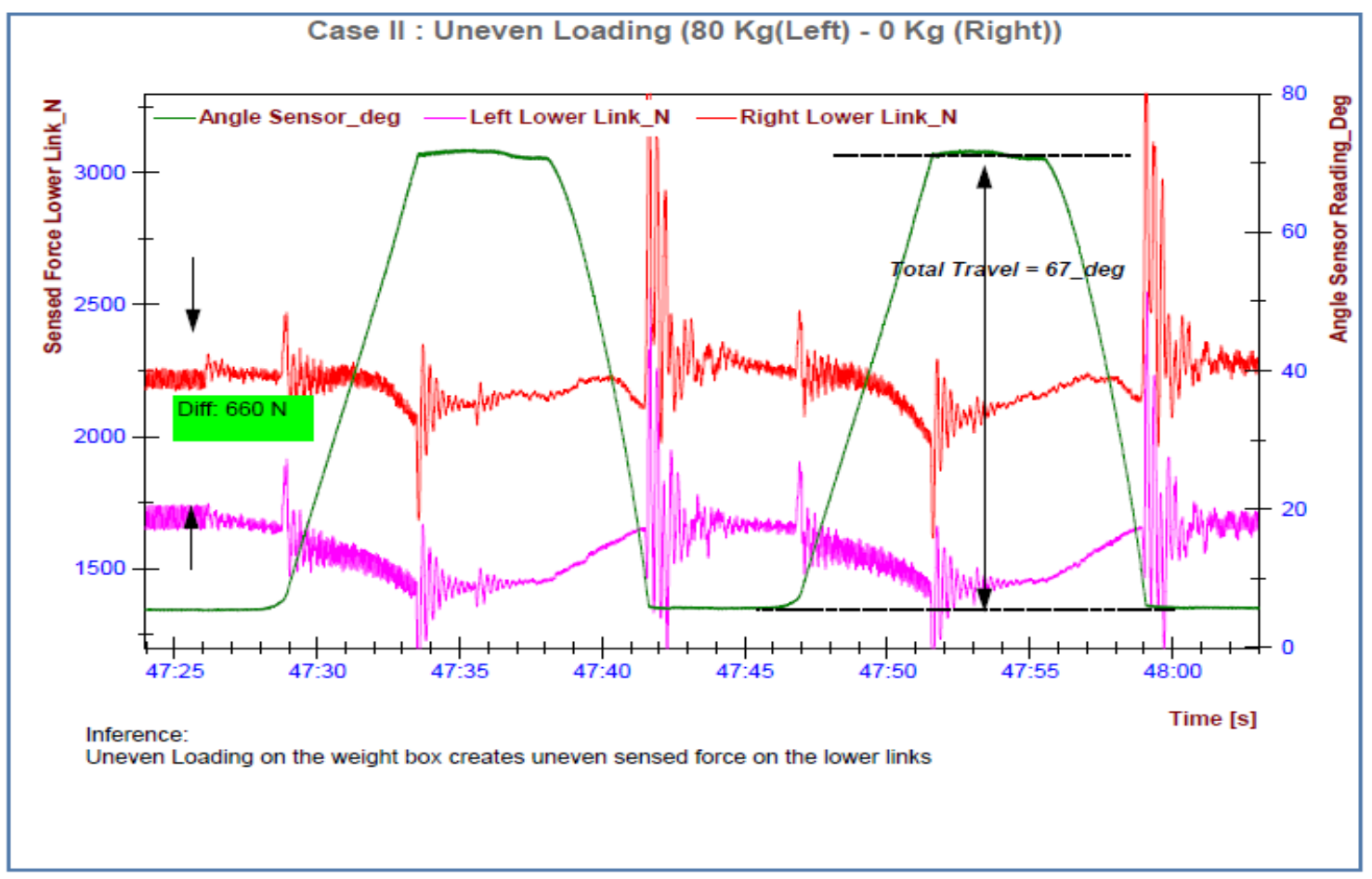

Figure.6(C) Load test - Comparative study

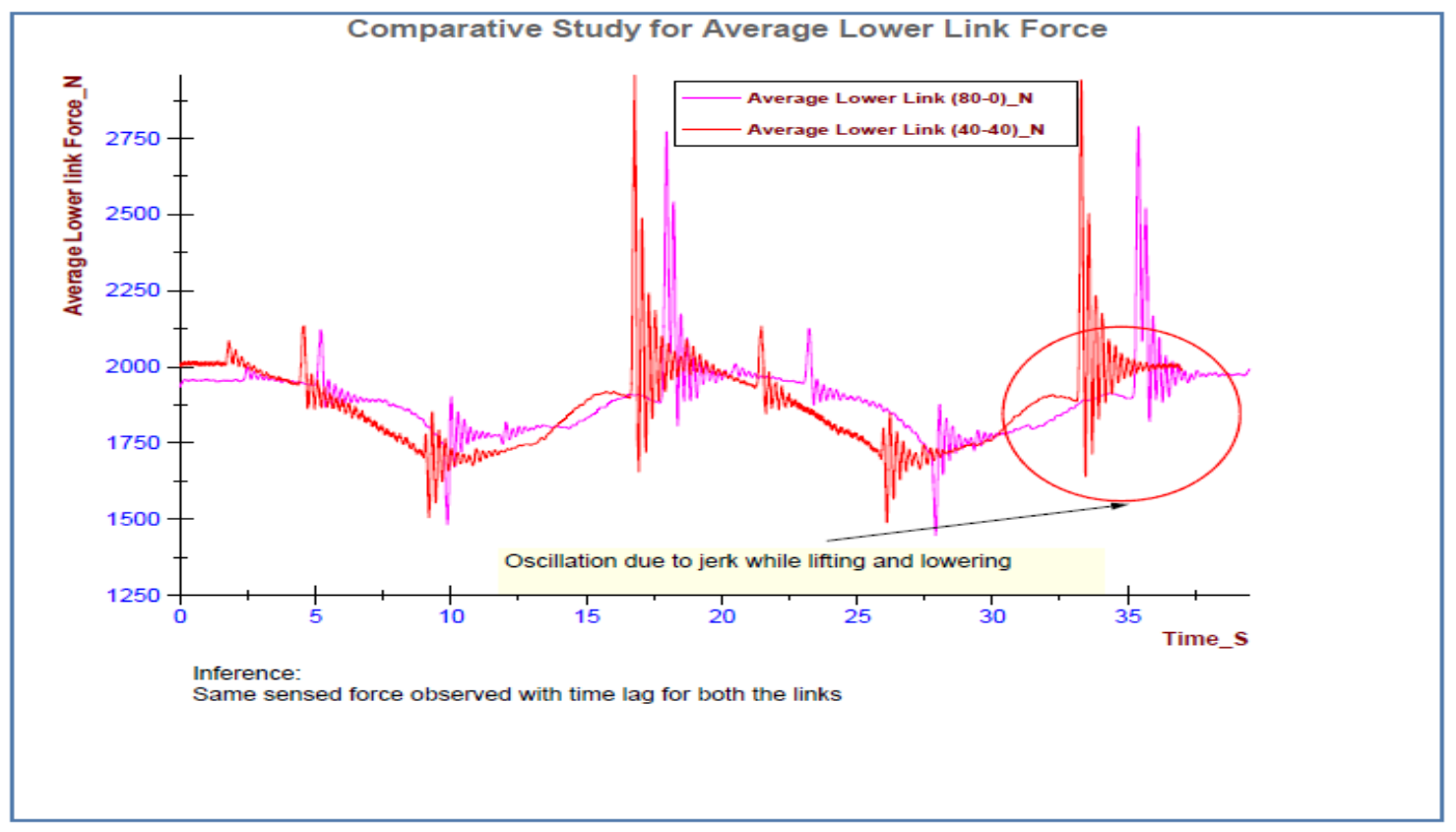


Fig.7 Field testing - Averaging of sensed forces

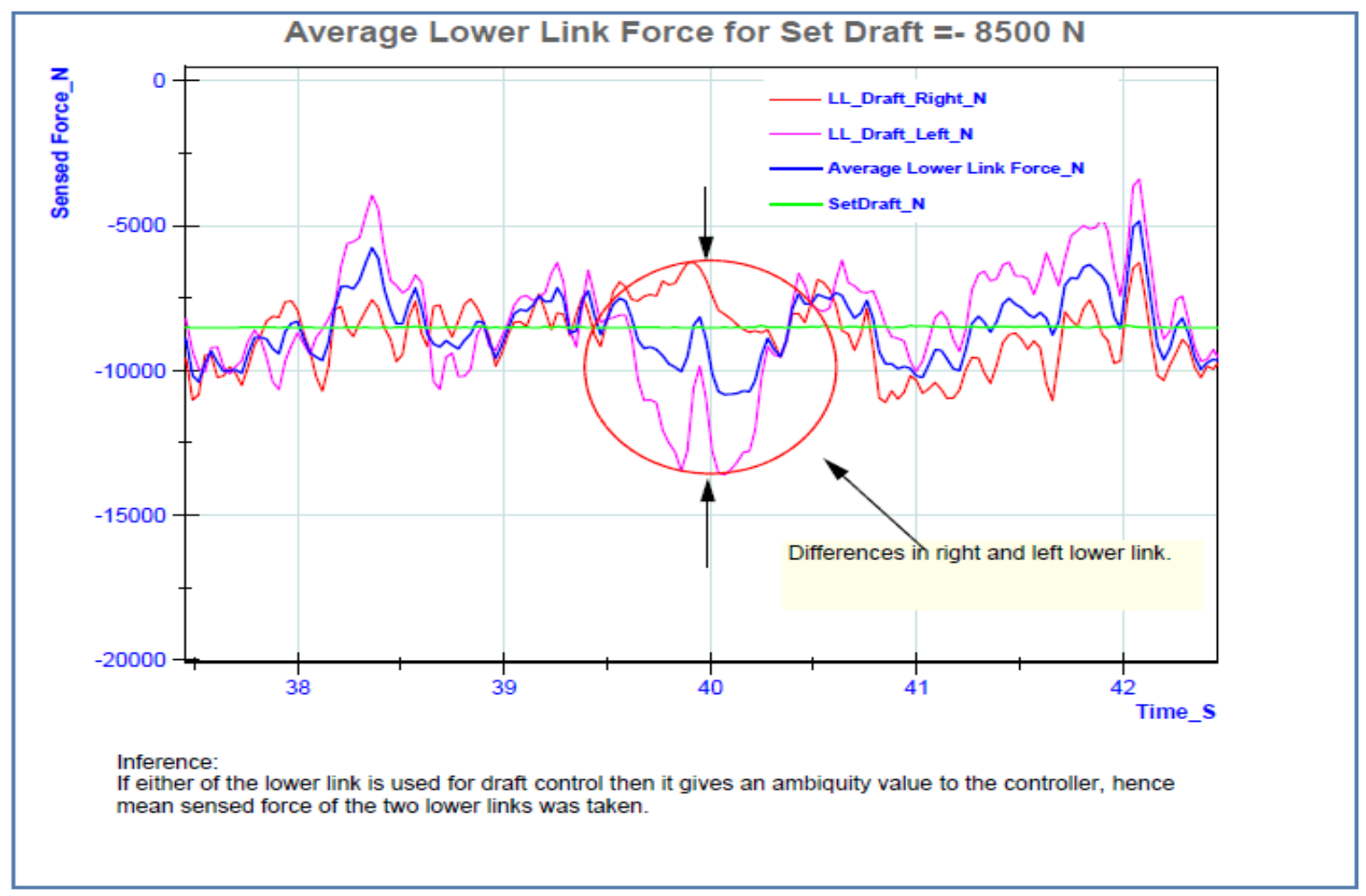

\section{Field testing}

Figure 7 explains why averaging of the lower link sensed force is required. If either of the two lower links is sensed then there is a possibility that a situation may arise as shown in the red circle region, where the difference between left and right lower link sensed force is large. If in that region right lower link force is sensed then implement will go down to attain set draft, whereas if left lower link is sensed then implement will lift, this provides ambiguity values to the controller, hence averaging of the lower link sensed force is done in straight ahead condition. It can be observed in the above figure that the profile of the left and right lower link sensed force and the average of them is the same, except in the red circled zone which is due to encountering different soil strength on the either sides.
It can be concluded from both the weight box testing and field testing that for lower link Draft sensing for it is necessary to average out the draft forces on both the links otherwise it will provide ambiguity to the controller and there would be wrong sensing od draft phenomenon.

\section{References}

1. Dobrinska, D., "Development of EHH for Case 4WD Tractors," SAE Journal, 1980, ISSN: 0146-7292; ISSN No.:862155.

2. Pranav, P.K., Tewari, V.K., Kumar, M., and Jha, K.R., (2012) "Automatic Wheel Slip Control System for Field Operation in 2WD Tractors," Computer and Electronics in Agriculture 84(1-6), 2012, doi:10.1016/j.compag.2012.02. 002.

3. Rutkowsky, D., (1987) “The Development 
of an Electronic Draft Control System," SAE Technical Paper 800238, 1987, doi:10.4271/861037.

4. Bardy, B., Babacz, W., Searcy, S., and Stout, B., (1986) "Measurement of Three Point Hitch Forces on Agricultural Tractor," SAE Technical Paper 861255, doi:10.4271/861255.
5. Singha P.S., et al., (2020) "Study on Sensitivity of Lower Link and Top Link Draft Sensing in Electrohydraulic Hitch Control System". International Journal of Agriculture Sciences, Volume 12, Issue 9, pp.- 9806-9809.

\section{How to cite this article:}

Singha, P.S., S. Baishya and Sahu, R. 2020. Significance of Averaging the Lower Link Sensed Forces for Draft Control in Electro-Hydraulic Systems. Int.J.Curr.Microbiol.App.Sci. 9(06): 1504-1511. doi: https://doi.org/10.20546/ijcmas.2020.906.185 